\title{
Immunocytochemical Properties of Alzheimer Straight Filaments
}

\author{
George Perry, Paul Mulvihill, Valeria Manetto, Lucila Autilio-Gambetti, and Pierluigi Gambetti \\ Division of Neuropathology, Institute of Pathology, Case Western Reserve University, Cleveland, Ohio 44106
}

In addition to paired helical filaments (PHF), the Alzheimer neurofibrillary tangle (NFT) contains straight filaments measuring $10-15 \mathrm{~nm}$ in width, as well as amorphous material. In previous immunoelectron microscopic studies, we have demonstrated that PHF and the amorphous material share antigens with the microtubule associated protein, tau, and the $200 \mathrm{kDa}$ subunit of neurofilaments (NF). The present immunoelectron microscopic study focuses on the antigens present in the straight filaments contained in the NFT. Indirect and direct immunogold staining of Vibratome sections of Alzheimer hippocampus with a monoclonal antibody to NF200 kDa (1.1.1.) and polyclonal antibodies to NF, tau, and to PHF yielded intense and specific reaction with NFT. Within the same NFT both straight filaments and PHF were decorated by all the antibodies. Similarly decorated within NFT were filaments displaying a transitional form between straight filaments and PHF. Both PHF and straight filaments were also recognized by all the antibodies after extraction with an ionic detergent. These findings show that straight filaments contain most, if not all, of the antigens known to be present in PHF and share with PHF insolubility in ionic detergents. It is suggested that straight filaments result from alternative pathways of organization of the same components as form the PHF.

Neurofibrillary tangles (NFT) and senile plaques are 2 of the most striking lesions observed in the brains from patients with Alzheimer disease. The chemical nature and mode of formation of the NFT has been an area of active investigation. These studies have been hindered by the inherent insolubility of NFT (Selkoe et al., 1982) and the lack of a pure NFT fraction. Immunocytochemical studies, however, have demonstrated normal cellular components within NFT. Antibodics to tau and some to neurofilaments stain NFT, but those to other identified neuronal components do not. Until recently these studies were performed at the light microscope and did not provide the resolution necessary to identify the NFT components recognized by the antibodies. Alzheimer NFT are primarily composed of paired helical filaments (PHF) but also contain 10-15 nm straight filaments and amorphous components (Hirano et al., 1968; Me-

Received Mar. 9, 1987; revised Apr. 27, 1987; accepted Apr. 30, 1987.

This work was supported by National Institutes of Health Grant AG00795 and the David S. Ingalls Fund. Dr. Manetto is the recipient of a fellowship from the Britton Fund. We thank M. Johnstone for technical assistance, M. Weiss, D. H Kang, S. Quinones, and M. Flynn for assistance in preparing the manuscript, and Dr. D. Selkoe for providing the serum to Alzheimer paired helical filaments.

Correspondence should be addressed to George Perry, Division of Neuropathology, Institute of Pathology, Case Western Reserve University, 2085 Adelbert Road, Cleveland, $\mathrm{OH} 44106$.

Copyright (C) 1987 Society for Neuroscience $0270-6474 / 87 / 113736-03 \$ 02.00 / 0$ tuzals et al., 1981, 1984; Yagashita et al., 1981 Yoshimura, 1984). Immunocytochemical studies performed at the ultrastructural level with the immunoperoxidase method have demonstrated that cytoskeletal epitopes are present in PHF and amorphous components (Perry et al., 1985; Wood et al., 1986). These studies have not addressed the issue of the presence of cytoskeletal epitopes in Alzheimer NFT straight filaments because immunoperoxidase reaction product does not allow one to distinguish well between straight filaments and PHF.

In this study, we use immunogold decoration in intact tissuc sections, and detergent-extracted NFT fractions to demonstrate that the Alzheimer NFT straight filaments contain the same epitopes as Alzheimer PHF. The straight filaments are, like $\mathrm{PHF}$, insoluble in an ionic detergent and maintain all their identified epitopes after such treatment. These results suggest that straight filaments and PHF of the Alzheimer NFT contain the same known cytoskeleton components.

\section{Materials and Methods}

Tissue source. Hippocampus from 4 patients, all with a definite history of dementia and fulfilling the NIA consensus criteria for Alzheimer disease (Khachaturian, 1985), were used. Tissuc was fixed with $10 \%$ formalin in $0.1 \mathrm{~m}$ phosphate buffer, $\mathrm{pH}$ 7.0. Prior to use, it was rinsed in PBS and $60 \mu \mathrm{m}$ free-floating sections were cut with a Vibratome (Oxford).

Antibodies. The following antibodies were used: (1) mouse antiserum recognizing all 3 neurofilament subunits (Gambetti et al., 1983), (2) monoclonal antibody 1.l.l. reacting with the $M_{r} 200 \mathrm{kDa}$ neurofilament subunit (Autilio-Gambetti et al., 1983; Gambetti et al., 1987), and (3) rabbit antiserum to the microtubule protein associated protein tau (ICN) (Perry et al., 1985; Gambetti et al., 1987), and (4) rabbit antiserum to paired helical filaments (Ihara et al., 1983; Kosik et al., 1986). In previous studies all these antibodies have been shown to react with NFT (Perry et al., 1985, 1986). Normal nonimmune rabbit serum, normal nonimmune mouse serum, and a monoclonal antibody specific for a Sendai virus protein or BS $\Lambda$ were substituted for the primary antibody in control preparations.

Immunogold staining. Vibratome sections were treated at room temperature for 10 min with $0.5 \%$ Triton $X-100$ in $0.15 \mathrm{M} \mathrm{NaCl}, 50 \mathrm{~mm}$ Tris- $\mathrm{HCl}, \mathrm{pH}$ 7.6. They first were rinsed and then incubated in the primary antibody for $2 \mathrm{~d}$ at $4^{\circ} \mathrm{C}$ followed by rinsing and subsequent incubation with the appropriate colloidal gold antibody complex. Colloidal gold was produced by citrate reduction and complexed to affinitypurified goat anti-mouse IgG (Southern Laboratories) or affinity-purified anti-rabbit IgG (Cappel Laboratories) (DeMay, 1983). Alternatively, antibody 1.1.1. was complexed directly to colloidal gold and incubated with the sections. Sections were subsequently fixed in $2.5 \%$ glutaraldehyde in $0.1 \mathrm{M}$ phosphate buffer ( $\mathrm{pH} \mathrm{7.2)}$ for $2 \mathrm{hr}$ followed by postfixation in $2 \% \mathrm{OsO}_{4}$ and flat-embedded in Spurr's medium. Sections were viewed at $60 \mathrm{kV}$ in a JEOL $100 \mathrm{CX}$ electron microscope.

Immunodecoration of SDS-treated NFT fractions. Gray matter from the hippocampus of an Alzheimer patient that was stored unfixed at $-70^{\circ} \mathrm{C}$ was homogenized and treated with SDS as previously described (Perry et al., 1985). The insoluble material was applied to carbon-coated nickel grids and incubated for $1 \mathrm{hr}$ with the primary antibodies or controls outlined above and followed by a $1 \mathrm{hr}$ incubation with secondary antibodies conjugated to colloidal gold. All the incubations were 

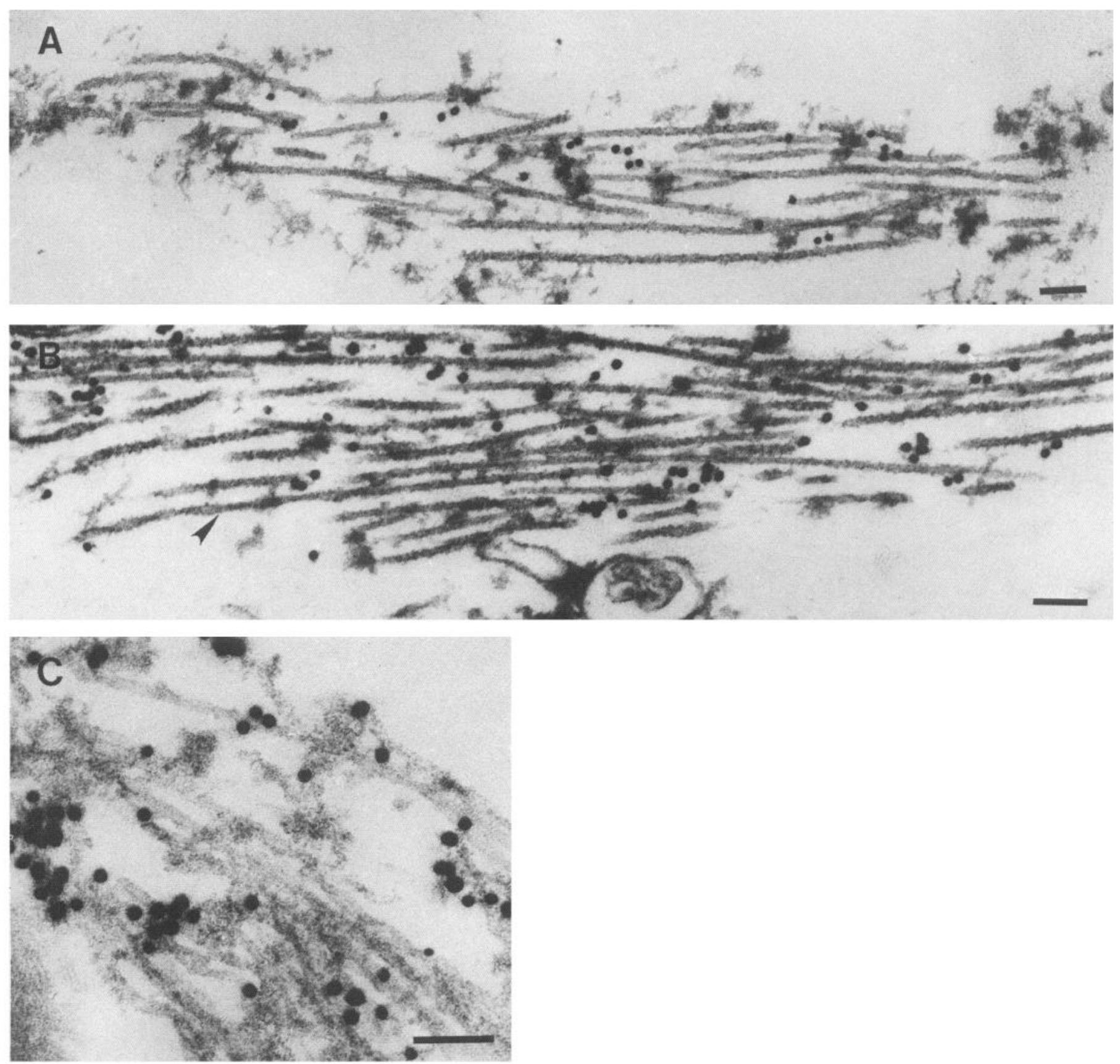

Figure 1. Immunogold decoration of Alzheimer NFT with $(A)$ antisera to tau, $(B)$ antisera to Alzheimer PHF, $(C)$ monoclonal antibody to NF $200 \mathrm{kDa}$ subunit (1.1.1). $A$ and $B$, Indirect colloidal gold; $C$, direct colloidal gold. Sections were electron-contrasted with uranyl acetate and lead citrate. Arrow in $B$ indicates a PHF possibly continuous with a straight filament (see text). $\times 78,300(A), 86,400(B), 132,500(C)$. Scale bar, $0.1 \mu \mathrm{m}$.

at room temperature and were followed by 3 rinses with $1 \%$ BSA in $0.15 \mathrm{M} \mathrm{NaCl}, 50 \mathrm{~mm}$ Tris- $\mathrm{HCl}, \mathrm{pH}$ 7.6. Immunostained preparations were negatively stained with $2 \%$ uranyl acetate. Grids were viewed at $80 \mathrm{kV}$ in a JEOL $100 \mathrm{CX}$ electron microscope.

\section{Results and Discussion}

Although the predominant filament type of the NFT in the investigated cases was PHF, $15 \mathrm{~nm}$ straight filaments were also present in most NFT. NFT primarily composed of straight filaments and PHF were infrequently noted. In addition, filaments transitional between straight filaments and PHF were observed.
The gold immunodecoration of NFT was visible in the light microscope as a red stain (not shown). At the ultrastructural level, NFT components recognized by the various antibodies could be identified. The antibodies to PHF, tau, and mono- and polyclonal antibodies to neurofilaments (NF) all decorated PHF and the straight filaments within Alzheimer NFT (Fig. 1). The antibodies also recognized filaments that seemed to be transitional forms between PHF and straight filaments. In some cases, apparent continuity was noted between straight filaments and PHF, with both the straight and helical portions of the filament being recognized by the same antibodies (Fig. $1 B$ ). Definitive 

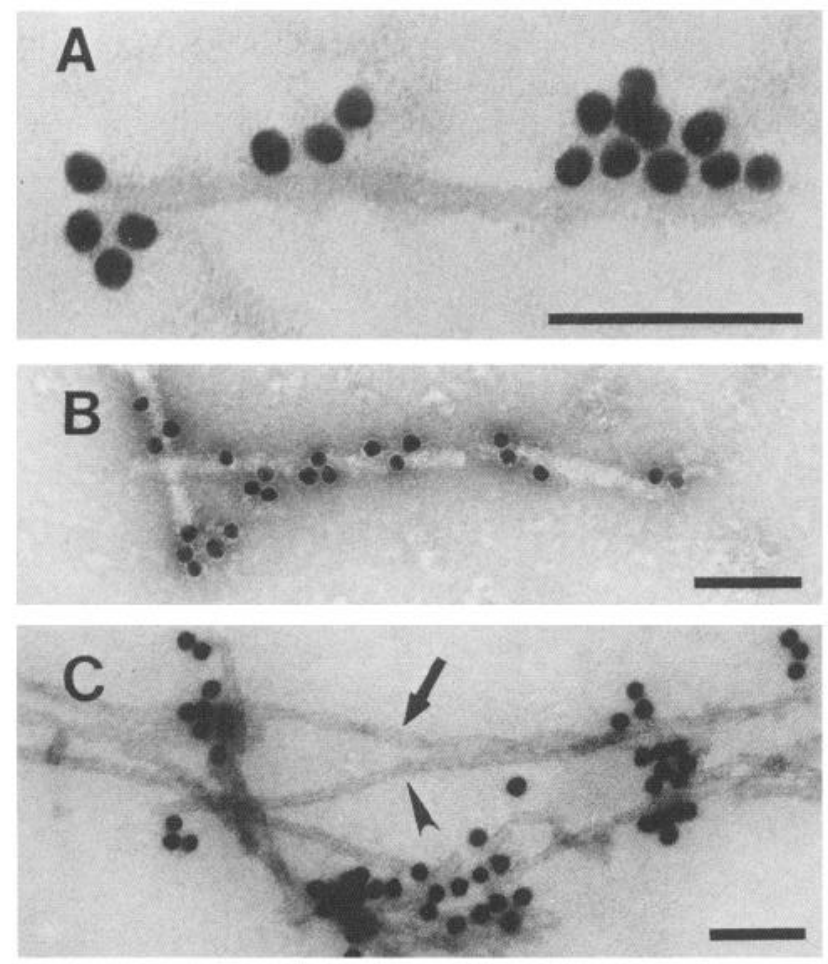

Figure 2. Indirect immunogold decoration of SDS-extracted Alzheimer straight filaments. Various primary antibodies were used to decorate straight and PHF. $A$, Rabbit antiserum to tau. $B$, Rabbit antiserum to PHF. $C$, Monoclonal antibody 1.1 .1 . to the $M, 200 \mathrm{kDa}$ neurofilament subunit decorated both straight (arrowhead) and paired helical filaments (arrow) in this preparation, which was suboptimally labeled so as not to obscure filament structure. Negatively stained with $2 \%$ uranyl acetate. $\times 256,000(A), 107,500(B), 97,500(C)$. Scale bar, $0.1 \mu \mathrm{m}$.

resolution of continuity would require tilt-stage analysis to rule out the possibility of superposition of 2 overlying filaments.

Few gold particles were present on structures outside NFT, although 1.1.1., and the antisera to neurofilaments did decorate neurofilaments present within axons (data not shown). No decoration of NFT components was observed when either nonimmune rabbit serum, nonimmune mouse serum, or a monoclonal antibody specific for a Sendai virus protein or BSA was substituted for the primary antibody in control preparations.

Preparations of SDS-extracted Alzheimer NFT filaments also contain $15 \mathrm{~nm}$ straight filaments in addition to PHF. All the antibodies used in this study immunodecorated the SDS-extracted straight filaments (Fig. 2) and PHF but not the cerebral amyloid also present in these preparations.

The present study demonstrates that the straight filaments and PHF found within the Alzheimer NFT share all their identified epitopes and solubility properties. These findings are relevant to the origin of PHF. They suggest that straight filaments and PHF result from a different organization of the same components. These constituents are likely to have undergone similar modifications since both are components of the same neuronal cytoplasmic inclusion and have the same insolubility characteristics. It is tempting to suggest that components leading to NFT filaments can polymerize to either straight filaments or PHF. Evidence for this can also be found in the filaments of Pick bodies, which share with Alzheimer PHF all their identified epitopes and solubility characteristics (Perry et al., 1987). The predominant component of the Pick body is a $12-15 \mathrm{~nm}$ straight filament, although PHF are also present. This observation leads us to speculate that the pathological conditions that lead to NFT filaments in Alzheimer disease yield predominantly PHF, as opposed to those in Pick disease, which yield predominantly straight filaments. Metuzals and coworkers (Metuzals et al., 1984; Metuzals, 1985) have reported that occasional PHF are continuous with $10 \mathrm{~nm}$ neurofilaments in NFT. This continuity might have been between PHF and $15 \mathrm{~nm}$ straight filaments rather than $10 \mathrm{~nm}$ neurofilaments. Were this the case, it would be additional indirect evidence that PHF and $15 \mathrm{~nm}$ straight filaments are related.

\section{References}

Autilio-Gambetti, L., P. Gambetti, and R. C. Crane (1983) Paired helical filaments: Relatedness to neurofilaments shown by silver staining and reactivity with monoclonal antibodies. In Biological Aspects of Alzheimer's Disease, R. Katzmann, ed., pp. 117-124, Cold Spring Harbor Laboratory, New York.

DeMay, J. (1983) Colloidal gold probes in immunocytochemistry. In Immunocytochemistry, J. M. Polak and S. Van Noorden, eds., pp. 82-112, Wright, Bristol, UK.

Gambetti, P., L. Autilio-Gambetti, G. Perry, G. Shecket, and R. C. Crane (1983) Antibodies to neurofibrillary tangles of Alzheimer's disease raised from human and animal neurofilament fractions. Lab. Invest. 49: 430-435.

Gambetti, P., L. Autilio-Gambetti, V. Manetto, and G. Perry (1987) Composition of paired helical filaments of Alzheimer disease as determined by specific probes. In Banbury Report, P. Davies, ed., Cold Spring Harbor, New York (in press).

Hirano, A., H. M. Dembitzer, L. T. Kurland, and H. M. Zimmerman (1968) Fine structure of some intraganglionic alterations. J. Neuropathol. Exp. Neurol. 27: 167-182.

Ihara, Y., C. Abraham, and D. J. Selkoe (1983) Antibodies to paired helical filaments in Alzheimer's disease do not recognize normal brain proteins. Nature 304: 727-730.

Khachaturian, Z. S. (1985) Diagnosis of Alzheimer's disease. Arch. Neurol. 42: 1097-1105.

Kosik, K. S., C. L. Joachim, and D. J. Selkoe (1986) Microtubuleassociated protein tau is a major antigen component of paired helical filaments in Alzheimer disease. Proc. Natl. Acad. Sci. USA 83: 4044-4048.

Metuzals, J. (1985) Neurofilaments and paired helical filaments. In Proc. 43rd Annu. Meet. Electron Microsc. Soc. Am., G. W. Bailey, ed., pp. 740-743, San Francisco Press, San Francisco, CA.

Metuzals, J., V. Montpetit, and D. F. Clapin (1981) Organization of the neurofilamentous network. Cell Tissue Res. 214: 455-482.

Metuzals, J., D. F. Clapin, and V. Montpetit (1984) Formation of paired helical filaments in Alzheimer's disease. In Proc. Electron Microsc. Soc. Am., G. W. Bailey, ed., pp. 532-533, San Francisco Press, San Francisco, CA.

Perry, G., N. Rizzuto, L. Autilio-Gambetti, and P. Gambetti (1985) Paired helical filaments from Alzheimer disease patients contain cytoskeletal components. Proc. Natl. Acad. Sci. USA 82: 3916-3920.

Perry, G., D. J. Selkoe, B. R. Block, D. Stewart, L. Autilio-Gambetti, and P. Gambetti (1986) Electron microscopic localization of Alzheimer neurofibrillary tangle components recognized by an antiserum to paired helical filaments. J. Neuropathol. Exp. Neurol. 45: 161168.

Perry, G., D. Stewart, R. Friedman, V. Manetto, L. Autilio-Gambetti, and P. Gambetti (1987) Filaments of Pick's bodies contain altered cytoskeletal elements. Am. J. Pathol. 127: 559-568.

Selkoe, D. J., Y. Ihara, and F. Salazar (1982) Alzheimer disease: Insolubility of purified paired helical filaments in sodium dodecyl sulfate and urea. Science 215: 1243-1245.

Wood, J. G., S. S. Mirra, N. J. Pollock, and L. I. Binder (1986) Neurofibrillary tangles of Alzheimer disease share antigenic determinants with the axonal microtubule-associated protein tau $(\tau)$. Proc. Natl. Acad. Sci. USA 83: 4040-4043.

Yagashita, S., Y. Itoh, W. Nan, and N. Amano (1981) Reappraisal of the fine structure of Alzheimer's neurofibrillary tangles. Acta Neuropathol. (Berl.) 54: 239-246.

Yoshimura, N. (1984) Evidence that paired helical filaments originate from neurofilaments. Clin. Neuropathol. 3: 22-27. 